\title{
Use of Cooling Thermal Storage as a Heat Sink for Steam Power Plant*
}

\author{
Ahmed Sabry HEGAZY** \\ ${ }^{* *}$ Mech. Engg. Dept., Menoufia University, Shebin Al Kom, Egypt, \\ Current address: P.O. Box 26240, Riyadh 11486, KSA, \\ e-mail: ahegazy7@yahoo.com
}

\begin{abstract}
In the present paper, a system is proposed for improving the performance of steam power plant with air-cooled condenser during peak loads. In this system, the power plant comprises two steam turbines, and the air-cooled condenser is replaced by two condensers. The first one is air-cooled (dry) and used for condensing the exhaust steam of the first turbine, while the second is water-cooled and serves to condense the steam outlet of the second turbine. The warm cooling water exiting the wet condenser is pumped to a cooling storage container, where it is cooled and re-circulated to the wet condenser. Cooling is produced by a refrigeration machine driven by the extra electric power generated by the two turbines during the time of the off-peak-loads (low electricity rates). Simple energy analyses have been developed to predict the energy characteristics of this system. The results of this paper showed that the proposed system leads to improving the plant power output at peak-loads. About 6, 16, 24 and $33 \%$ increase in generated plant power can be achieved at peak-loads (high electricity rates) when the ambient temperature is 20 , 30,40 and $50{ }^{\circ} \mathrm{C}$ respectively, and the whole steam exiting both turbines is cooled in a wet condenser to a design temperature of $20^{\circ} \mathrm{C}$. The results showed also that choice of the capacity of each turbine is essentially affected by the quality of the refrigeration machine and ambient temperature.
\end{abstract}

Key words: Steam Power Plant, Heat Sink, Cooling Thermal Storage, Wet Condenser, Air-Cooled Condenser, Refrigeration Machine

\section{Introduction}

The condenser is an essential part of any steam power plant. Its function is to condense the exhaust steam from the steam turbine by rejecting the heat of vaporization to the cooling medium as waste. This rejection occurs in most steam power plants in recirculating water-cooled condensers. The circulation rate of cooling water in such a condenser amounts to about $1.5 \mathrm{~m}^{3} / \mathrm{min}$ for each $\mathrm{MWe}$, and the circulating water requires a supply water make-up rate of about 5 percent. ${ }^{(1)}$

Many areas of the world are susceptible to severe freshwater shortages as a result of drought, growing populations and increasing demand. These areas use dry cooling (aircooled) condenser as an alternative to the water-consuming wet condenser, where heat is rejected to air without any loss of water. The steam condensing pressures and temperatures of a dry cooled unit are significantly higher than a wet cooled unit, due to the low heat transfer rates of dry cooling and operation at the dry bulb temperature rather than the wet bulb one. Most of the areas using dry condensers are characterized by high ambient temperature during the period of peak-loads, which results in a substantial power output loss. There is little current research and development work being reported in the literature 
on dry cooling systems for power plants. A few important exceptions include improved heat exchanger geometries for finned tube bundles in air-cooled condensers (2), (3); enhancement of air-cooled condenser performance with the use of limited water ${ }^{(4),(5)}$; the use of evaporative condenser ${ }^{(6)}$; and optimization techniques. ${ }^{(7)}$

The concept of ammonia dry cooling system is reported in. ${ }^{(8)}$ The system is an indirect type, in which the usual circulating water loop is replaced by a phase-change ammonia loop where the ammonia is evaporated in the tubes of the steam condenser and condensed in an air-cooled condenser. The concept was tested and well documented. ${ }^{(8),(9),}$ (10), (11) In steam plants applying this concept, most of the generated power would be used for driving the refrigerant compressor during peak-loads. This would result in a great deficiency in the generated power so that the demanding load would not be covered.

In ${ }^{(14)}$ an approach is proposed to improve the performance of air-cooled condenser of a combined cycle power plant. In this approach, a chilled-water thermal energy storage system is used to pre-cool the inflow air to the air-cooled condenser whenever the ambient air temperature increases above the designed air temperature. The temperature of the chilled water thermal storage system is maintained by an absorption refrigeration system. This system can function efficiently only in a relatively cold weather where the air temperature rises above the design one for short periods, otherwise a very big storage space is needed for storing the chilled water. Meanwhile, the condenser of large capacity absorption refrigeration system calls for use of cooling water rather than air.

A new approach is proposed in the current paper that has potential to take advantage of the high performance of wet cooling and increase plant power output at peak-loads. In this approach, a portion of exhaust steam of the steam power plant is cooled in a water condenser rather than dry one and the heat gained is dissipated in a cooling thermal storage container. Cooling is produced by a refrigeration machine driven by the extra electric power generated by the plant during the off-peak-loads (low electricity rates). A portion of the produced cooling is used directly in the wet condenser during off-peak-loads, while the rest is stored to be used in the wet condenser with the refrigeration machine being stopped during the period of peak-loads. This enables the wet condenser to operate at much lower temperature and pressure, which results in increasing the power output of the steam plant at peak loads (high electricity rates), since no energy is consumed for operating the refrigeration machine through this period. As a matter of fact, the method of using cooling thermal storage to increase the generated power output during peak-loads has been successfully applied to gas turbines for long time. ${ }^{(13)}$ It is to be noticed that cooling thermal storage allows the utility to generate more of its electricity with its most efficient generators (during part-loads). In other words, cooling thermal storage allows small power plant to serve large loads for short intervals (peak-loads) by shifting the load to times of day when electricity rates are lower.

The current paper presents simple thermodynamic analyses for predicting the performance of a combined steam power plant and cooling thermal storage. The results obtained by aid of these analyses can represent the bases for judging the feasibility and profitability of using this system.

\section{Nomenclature}

$C O P$ refrigeration machine coefficient of performance

E energy

$h \quad$ specific enthalpy

$p \quad$ pressure

$\mathrm{kJ} / \mathrm{kg}$

pressure
Power

bar

$P \quad$ Power

$\mathrm{kW}$

$Q \quad$ heat rate

$\mathrm{kW}$

$R \quad$ power fraction defined by Eq. (1) 


\section{Greek letters}

$\Delta t_{p l} \quad$ time period of applying peak load

$\Delta t_{s} \quad$ time period for storing the cooling

$\eta_{o} \quad$ power plant overall efficiency

$\eta_{\text {th }} \quad$ steam cycle thermal efficiency

$\xi \quad$ cooling loss coefficient

\section{Subscripts}

$b \quad$ boiler

$b 1, b 2$ steam turbines whose condenser is dry and wet cooled respectively

$c$ condenser

$d \quad$ dry-cooled condenser

$d c \quad$ direct cooling

ev evaporator

$r \quad$ refrigeration machine

$s \quad$ cooling thermal storage

$t$ total power

$w \quad$ wet-cooled condenser

0 condenser design temperature

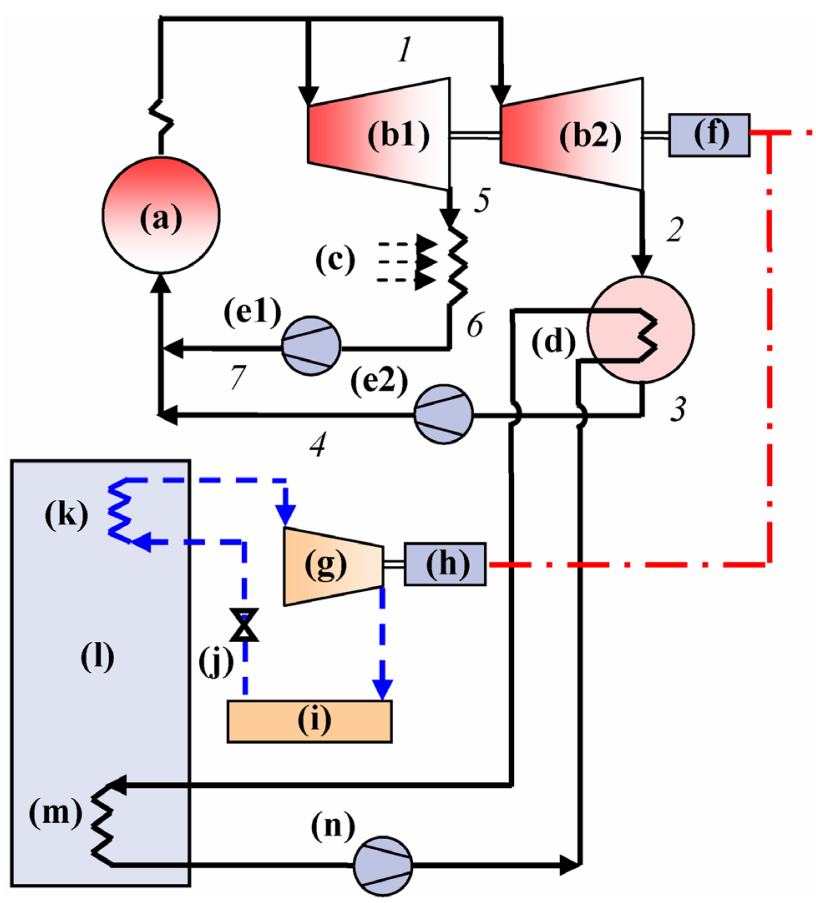

Fig. 1. Schematic diagram of the combined steam cycle and refrigeration machine with cooling thermal storage
(a) Boiler
(c) Air-cooled steam condenser
(e1), (e2) Boiler feed water pumps
(g) Refrigerant Compressor
(i) Refrigerant condenser
(k) Evaporator
(m) Heat exchanger

(b1), (b2) Steam turbines

(d) Water- cooled steam condenser

(f) Generator

(h) Motor

(j) Throttling valve

(l) Cooling storage container

- Water/Steam

(n) Refrigerant Circulating pump

-. Electricity 


\section{Concept of Combined Cooling Thermal Storage and Steam Power Plant}

The configuration of the proposed combined cooling thermal storage and steam power plant is shown schematically in Figure 1. This system consists of a steam power plant cycle and a refrigeration cycle. The steam cycle comprises two steam turbines and other auxiliaries (boiler, feed water heaters, condensers...), which constitute a modern steam power plant. Of these constituents only the boiler (a), steam turbines (b1) and (b2), air cooled condenser (c), water-cooled condenser (d), feed water pumps (e1) and (e2) and generator (f) are shown in Fig. 1. The air-cooled condenser (c) is used to condense the exhaust steam of the turbine (b1), while the water-cooled condenser (d) serves to condense the steam outlet of the turbine (b2). The corresponding T-s diagram of this cycle is shown in Figure 2. The numeric data of Fig. 1 correspond to the points 1 to 7 given in Fig. 2.

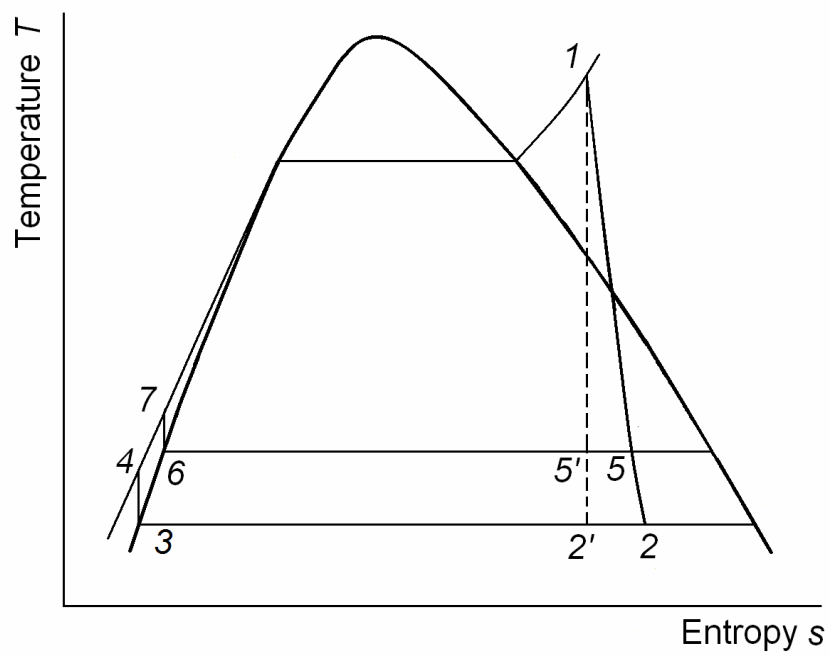

Fig. 2 Temperature - entropy diagram of the studied steam cycle

The refrigeration cycle comprises a compressor (g) driven by an electric motor $(\mathrm{h})$, a condenser (i), a throttling valve (j), an evaporator (k) and a cooling storage container (l). The motor (h) is provided with electric power from the generator (f). To limit the water consumption, the refrigerant condenser (i) is air-cooled. In this case the temperature of the refrigerant in the condenser is dependent on the ambient temperature and in general it can vary between $30-50{ }^{\circ} \mathrm{C}$. The cooling produced by the evaporator $(\mathrm{k})$ is stored in the cooling thermal storage container (l). The heat exchanger (m) serves to cool the hot cooling water coming out of the wet condenser (d).

The steam plant works continuously at full power (maximum efficiency), while the refrigeration machine is operated at periods of off-peak-loads making use of the power exceeding the demand of the end users. Hence, the refrigeration machine has three operating periods: the period of direct cooling, where all produced cooling goes for cooling the wet condenser; the period of storing the cooling, where a portion of the produced cooling is used for direct cooling of the wet condenser and the rest is stored in the cooling container; and the period of outage (peak-loads of the steam plant), where the refrigeration machine is stopped and the cooling of the wet condenser if effected by the stored cooling.

\section{Energy Analyses}

The aim of the energy analyses presented in this section is to predict the energy output of the combined steam power plant and cooling thermal storage under different operating conditions. For this purpose it is necessary to know the characteristics of the steam cycle 
implemented by each turbine. Generally, modern steam plants are using sophisticated steam cycles which include feed water heaters, re-heaters, etc. to assure high thermal efficiency. The details of these cycles are beyond the scope of the present paper. Therefore, the simple steam Rankin cycle, as shown in Figs. 1 and 2 is considered for the following analyses. The thermal and overall efficiency of the simple steam cycle and turbine respectively, are modified to take into account this assumption.

Referring to Figs. 1 and 2, the steam exiting the boiler of the plant with state 1 is expanded in the turbine (b1) to point 5 and turbine (b2) to point 2. If the state of the exhaust steam out of turbines (b1) and (b2) is at the design condition denoted by the subscript 0 , then the power generated by turbines (b1) and (b2) are $P_{b 1,0}$ and $P_{b 2,0}$ respectively. Hence, the power fraction $R$ is introduced by the following relation:

$$
R=\frac{P_{b 2,0}}{P_{b 1,0}+P_{b 2,0}}=\frac{P_{b 2,0}}{P_{t, 0}}
$$

where $P_{t, 0}$ is the total power $\left(P_{b 1,0}+P_{b 2,0}\right)$ generated by the power plant at the design condition of the exhaust steam temperature.

Obviously, the temperature of the exhaust steam of turbine (b2) can be cooled to the design temperature since the cooling water temperature can be controlled by the refrigeration machine/storage container. Accordingly, it is assumed throughout the following analyses that the power $P_{b 2, w}$ of the turbine (b2) with water-cooled condenser is equal to $P_{b 2,0}$ at the design condition. Moreover, it is assumed that the turbine internal efficiency, mechanical and generator efficiencies are the same for both turbines (b1) and (b2) and remain unchanged during the operation of the plant. Considering the above mentioned assumptions and neglecting powers of the pumps (e1) and (e2), it follows from Fig. 2. that:

$$
\frac{\eta_{o, 0}}{\eta_{o, d}}=\frac{\eta_{t h, 0}}{\eta_{t h, d}}=\left(\frac{h_{1}-h_{2^{\prime}}}{h_{1}-h_{5^{\prime}}}\right)\left(\frac{h_{1}-h_{6}}{h_{1}-h_{3}}\right)
$$

From Fig. 2 and by aid of Eq. (2), the following equation for power ratios can be derived:

$$
\frac{P_{b 1,0}}{P_{b 1, d}}=\frac{P_{b 2,0}}{P_{b 2, d}}=\frac{P_{b 2, w}}{P_{b 2, d}}=\frac{P_{t, 0}}{P_{t, d}}=\left(\frac{h_{1}-h_{2^{\prime}}}{h_{1}-h_{5^{\prime}}}\right)^{2}\left(\frac{h_{1}-h_{6}}{h_{1}-h_{3}}\right)
$$

In order to be able to calculate the average power of the refrigeration machine during the direct cooling period, it is first necessary to determine the rate of heat it removes from the wet condenser of the turbine (b2). The overall efficiency $\eta_{o, 0}$ of this turbine and the thermal efficiency of its steam cycle are defined as:

and

$$
\eta_{o, 0}=\frac{P_{b 2, w}}{Q_{b}}
$$

$$
\eta_{t h, 0}=\frac{Q_{b}-Q_{c}}{Q_{b}}
$$

Solving Eqs. (4) and (5) to get $Q_{c}$ results in:

$$
Q_{c}=\frac{P_{b 2, w}}{\eta_{o, 0}}\left(1-\eta_{t h, 0}\right)
$$

Given the coefficient of cooling loss $\xi$, then the rate of heat $Q_{e v, d c}$ to be removed by the evaporator of the refrigeration machine during the direct cooling period may be given in combination with Eq. (6) by:

$$
Q_{e v, d c}=\frac{P_{b 2, w}}{\eta_{o, 0}}\left(1-\eta_{t h, 0}\right)(1+\xi)
$$


The coefficient of performance $C O P$ of the refrigeration machine during this period is defined as:

$$
C O P=\frac{Q_{e v, d c}}{P_{r, d c}}
$$

Combination of Eqs. (7) and (8) results in:

$$
\frac{P_{r, d c}}{P_{b 2, w}}=\frac{\left(1-\eta_{t h, 0}\right)(1+\xi)}{\operatorname{COP} \eta_{o, 0}}
$$

The total power $P_{t, d c}$ of the power plant during the direct cooling is given by:

$$
P_{t, d c}=P_{b 2, w}+P_{b 1, d}-P_{r, d c}
$$

Dividing both sides of Eq. (10) by $P_{t, d}$ and then dividing both the nominator and dominator of the right hand side of the resulted equation by $P_{t, 0}$ and combining it with Eqs. (1), (3) and (9), the following equation can be derived:

$$
\frac{P_{t, d c}}{P_{t, d}}=R\left\{\left[\left(\frac{h_{1}-h_{2^{\prime}}}{h_{1}-h_{5^{\prime}}}\right)^{2}\left(\frac{h_{1}-h_{6}}{h_{1}-h_{3}}\right)\right]\left[1-\frac{\left(1-\eta_{t h, 0}\right)(1+\xi)}{\eta_{o, 0} C O P}\right]-1\right\}+1
$$

As for the period where the cooling thermal storage is executed, a portion of the cooling power generated by the refrigeration machine serves to cool the wet condenser of turbine (b2) and the rest is stored thermally in a storing container. The coefficient of performance $C O P$ of the refrigeration machine during this period is given as:

$$
C O P=\frac{Q_{e v, s}}{P_{r, s}}
$$

where $Q_{e v, s}$ and $P_{r, s}$ are the average heat rate to be removed by the evaporator and power of the refrigeration machine respectively, during the storing period.

From Eq. (12) $Q_{e v, s}$ is given by:

$$
Q_{e v, s}=P_{r, s} C O P
$$

Given that the time interval of storing process is $\Delta t_{s}$, the energy $E_{e v, s}$ to be removed by the evaporator of the refrigeration machine during the storing process is given in combination with Eq. (13) by:

$$
E_{e v, s}=Q_{e v, s} \Delta t_{s}=P_{r, s} C O P \Delta t_{s}
$$

$E_{e v, s}$ is equal to the heat energy removed from the wet condenser during the two periods of thermal storage and application of peak load and the heat transferred from the surroundings to the cooling container and the cooling medium conveying pipes. Hence, the following equation is valid:

$$
E_{e v, s}=P_{r, s} \operatorname{COP} \Delta t_{s}=Q_{c}(1+\xi)\left(\Delta t_{s}+\Delta t_{p l}\right)
$$

Substituting Eq. (6) into Eq. (15) and solving it to get $P_{r, s} / P_{b 2, w}$ leads to:

$$
\frac{P_{r, s}}{P_{b 2, w}}=\frac{1}{\operatorname{COP} \eta_{o, 0}}\left(1-\eta_{t h, 0}\right)(1+\xi)\left(\frac{\Delta t_{p l}}{\Delta t_{s}}+1\right)
$$

Similar to Eq. (11) the following equation can be derived

$$
\frac{P_{t, s}}{P_{t, d}}=R\left\{\left[\frac{h_{1}-h_{2^{\prime}}}{h_{1}-h_{5^{\prime}}}\right]^{2}\left[\frac{h_{1}-h_{6}}{h_{1}-h_{3}}\right]\left[1-\frac{1}{C O P \eta_{o, 0}}\left(1-\eta_{t h, 0}\right)(1+\xi)\left(\frac{\Delta t_{p l}}{\Delta t_{s}}+1\right)\right]-1\right\}+1
$$




\section{Results and Discussion}

The analyses described in the previous section have been used to predict the energy output of different configurations of combined cooling thermal storage and steam power plant under different ambient temperatures. The results presented hereafter are based on the basic design parameters of the steam power plant given in Table 1. It is to be noticed that the values of $\eta_{o, 0}$ and $\eta_{t h, 0}$ given in table 1 are approximately close to those of a real modern steam plant. Also, the value of $\xi$ in table 1 is valid for well insulated cooling storage container and cooling water conveying pipes. The values of $\eta_{o, 0}, \eta_{t h, 0}$ and $\xi$ were kept unchanged as given in table 1 for the whole calculations carried out in this study. The values of the other parameters given in table 1 were changed only when their effect is to be studied. The thermal properties of water and steam were determined as a function of pressure and temperature by aid of the soft ware associated with the text book ${ }^{(14)}$.

Table 1: Basic design data of the studied steam power plant

\begin{tabular}{l|c|c|c|} 
Boiler pressure & $p_{b}$ & bar & 150 \\
Steam temperature at inlet to the turbines & $T_{1}$ & ${ }^{\circ} \mathrm{C}$ & 500 \\
Steam temperature in the wet condenser & $T_{c}$ & ${ }^{\circ} \mathrm{C}$ & 20 \\
Rise of steam temperature in the dry condenser over & & & \\
ambient temperature & $\Delta T_{c}$ & ${ }^{\circ} \mathrm{C}$ & 8 \\
Steam plant overall efficiency at design condition & $\eta_{o, 0}$ & - & 0.35 \\
Thermal efficiency of Steam cycle at design condition & $\eta_{t h, 0}$ & - & 0.5 \\
Cooling loss coefficient & $\xi$ & - & 0.05
\end{tabular}

To show the effect of the ambient temperature $T_{a}$ on the power of the second turbine (b2), the power ratio $P_{b 2, w} / P_{b 2, d}$, calculated by using Eq. (3), is drawn in Figure 3 versus the ambient temperature $T_{a}$. $\quad$ Fig. 3 reveals clearly that the ratio $P_{b 2, w} / P_{b 2, d}$ is increased almost linearly with rising ambient temperature $T_{a}$. This can be interpreted as follows: As the ambient temperature rises, the steam temperature in the dry condenser increases and as a result the condenser pressure is elevated. This leads to reducing the turbine power, which results in raising the ratio $P_{b 2, w} / P_{b 2, d}$. The power ratio $P_{b 2, w} / P_{b 2, d}$ is increased from 1.0 at $T_{a}$ of $12{ }^{\circ} \mathrm{C}$ to $1.06,1.16,1.24$ and 1.33 at $T_{a}$ of $20,30,40$ and $50{ }^{\circ} \mathrm{C}$ respectively.

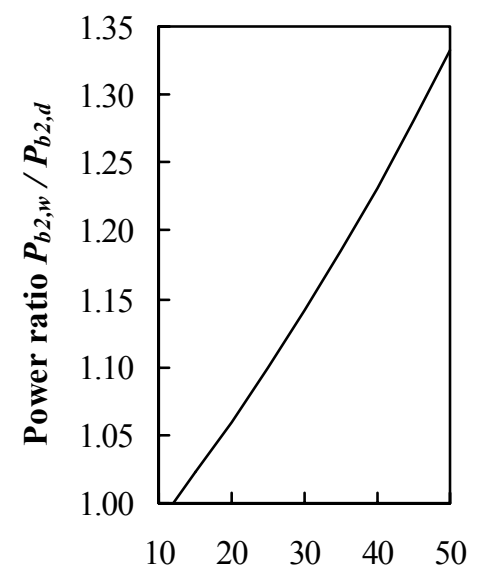

Ambient temp. $T_{a}{ }^{0} \mathrm{C}$

Fig.3 Relation between the second turbine power and ambient temperature

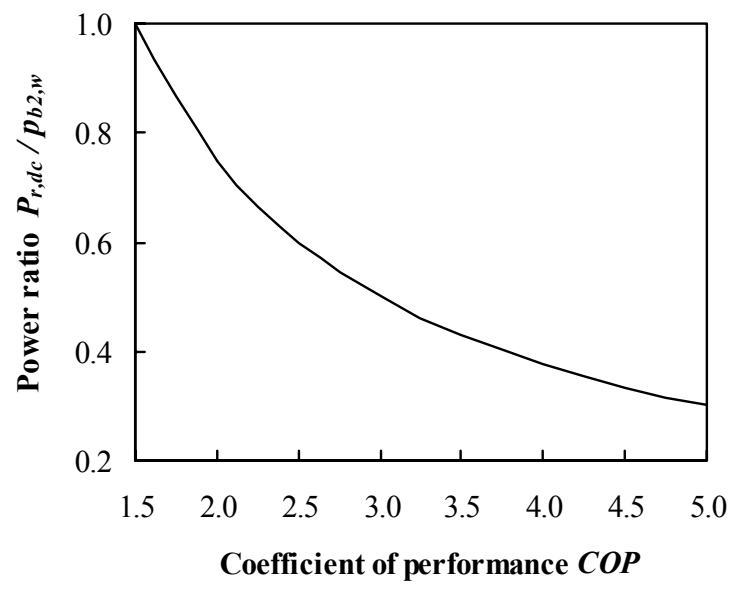

Fig. 4 Power of the refrigeration machine used for direct cooling of the water-cooled condenser as a function of coefficient of performance 
In Figure 4, the power ratio $P_{r, d c} / P_{b 2, w}$ determined by Eq. (9) is plotted against the coefficient of performance $C O P$ of the refrigeration machine. $P_{r, d c}$ is the power required for driving the refrigeration machine to generate cooling for direct use in the wet condenser. It is to be noticed that the power ratio $P_{r, d c} / P_{b 2, w}$ is dependent on neither power fraction $R$ nor ambient temperature $T_{a}$ as pointed out by Eq. (9). Fig. 4 shows obviously that $P_{r, d c} / P_{b 2, w}$ is receding sharply with growing $C O P$, especially at low values of $C O P$. The rate of decrease in $P_{r, d c} / P_{b 2, w}$ with $C O P$ declines gradually as $C O P$ grows up. It is clear from Fig.4 that all the power generated by the turbine (b2) is consumed in driving the refrigeration machine if COP equals 1.0. The ratio $P_{r, d c} / P_{b 2, w}$ drops to $0.78,0.6,0.45,0.39$ and 0.33 when $C O P$ is increased to $2.0,2.5,3.0,3.5$ and 4.0 respectively. During the direct cooling period, the refrigeration machine can produce chilled water since it can be directly used for cooling the steam condenser. This makes the evaporator temperature relatively high and as a result $C O P$ is expected to be large enough to make $P_{r, d c} / P_{b 2, w}$ reasonably low.

The behavior of the ratio $P_{r, d c} / P_{b 2, w}$ presented in Fig. 4 is greatly affecting the net total power $P_{t, d c}$ generated by the steam plant as shown in Figure 5 . In this figure the ratio $P_{t, d c} / P_{t, d}$ calculated by aid of Eq. (11) is plotted versus the coefficient of performance COP of the refrigeration machine for ambient temperature $T_{a}$ of $40{ }^{\circ} \mathrm{C}$ and for power fraction $R$ of $0.25,0.5,0.75$ and 1.0 . From this figure, both $R$ and $C O P$ affect greatly the power ratio $P_{t, d c} / P_{t, d}$ during direct cooling of the wet condenser. If $C O P$ is in a range less than 2.5 , and if $R$ is higher than 0.5 , the portion of the steam plant power available for end users will be relatively small. In this case, $R$ has to be chosen less than 0.5 . In the case of COP being greater than 2.5, the value of $R$ is determined based on the power demand of the end users. For the range of $C O P$ greater than 2.5, the portion of the power available for the end users is greater than $50 \%$ of the power generated by the steam plant when the turbines exhaust steam is wholly cooled in dry condenser.

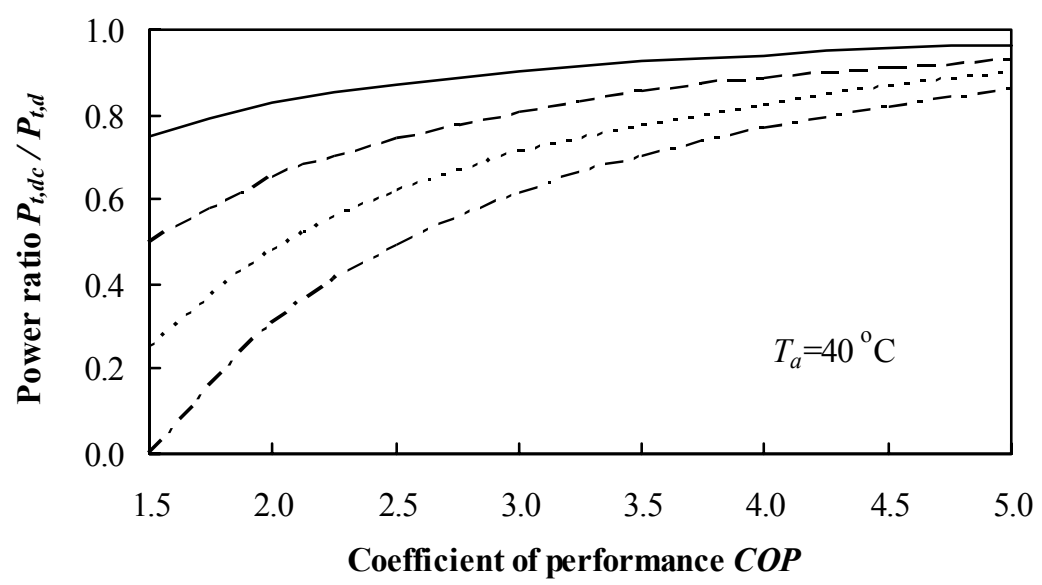

Fig. 5 Effect of the coefficient of performance on the net total power of the steam plant during direct cooling of the water-cooled condenser

$$
\begin{aligned}
& R=0.25 \\
& R=0.75
\end{aligned}
$$$$
\begin{array}{ll}
--- & R=0.5 \\
-.-.- & R=1.0
\end{array}
$$

Figure 6 shows the effect of the ambient temperature $T_{a}$ on the power ratio $P_{t, d c} / P_{t, d}$ for power fraction $R$ of $0.25,0.5,0.75$ and 1.0 , and for coefficient of performance $C O P$ of 2.0, 3.0 and 4.0. It is seen from Fig. 6 that the effect of $T_{a}$ on the ratio $P_{t, d c} / P_{t, d}$ is inconsiderably small at $C O P$ of 2.0, especially for low values of $R$. As $C O P$ exceeds 2.0, the effect of $T_{a}$ becomes more material, where $P_{t, d c} / P_{t, d}$ increases with rising value of $T_{a}$. 
The rate of increase in $P_{t, d c} / P_{t, d}$ with $T_{a}$ grows up as $R$ is raised. This can be attributed to the considerable reduction in $P_{t, d}$ with elevating ambient temperature, while the decrease in $P_{t, d c}$ is relatively small due to the unchanged power $P_{b 2, w}$ as a result of constant steam temperature in the wet condenser regardless of $T_{a}$ value.
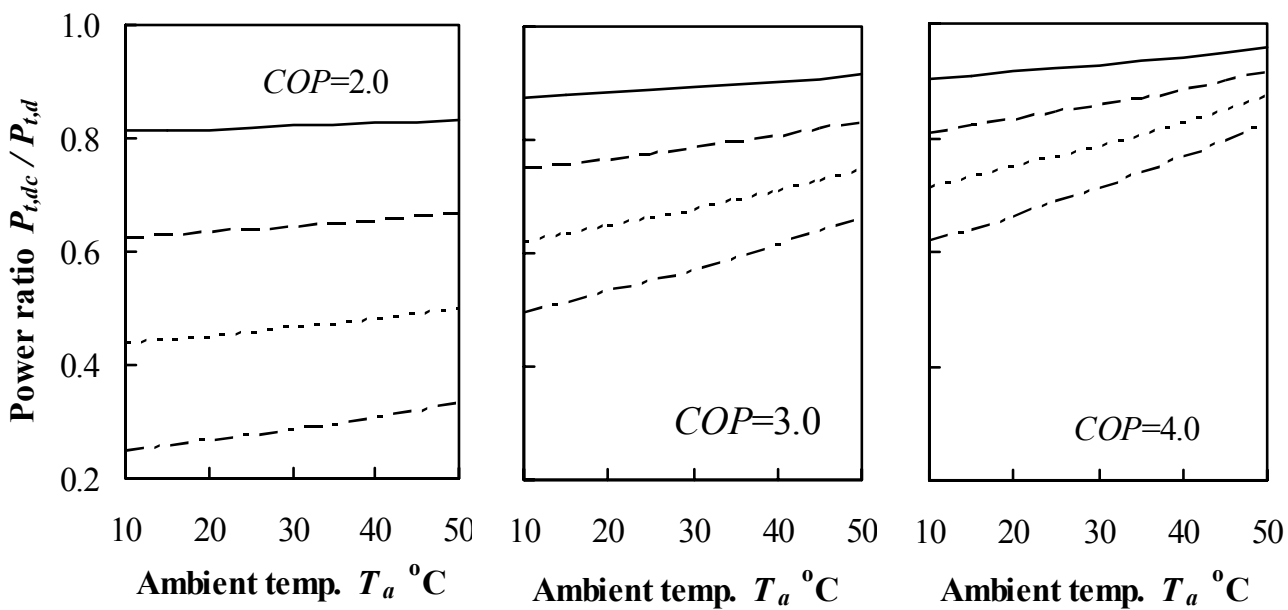

Fig. 6 Effect of the ambient temperature on the net total power of the steam plant for direct cooling of the water-cooled condenser

$$
\begin{array}{lll}
R=0.25 & --- & R=0.5 \\
R=0.75 & -.-. & R=1.0
\end{array}
$$

It can be inferred from Figs. 5 and 6 that reasonably high values of $P_{t, d c} / P_{t, d}$ is achieved when $C O P$ is great enough (larger than 2.5). This can occur if the refrigerating machine is driven at the possibly minimum condenser temperature and maximum allowable evaporator temperature. The former condition is imposed by the weather conditions and can not be controlled, but the latter one necessitates the use of the refrigeration machine to produce chilled water rather than ice. This chilled water is used directly for cooling the wet condenser without any storage.

In Figure 7, the ratio $P_{r, s} / P_{b 2, w}$ of the average power used for driving the refrigeration machine to the power generated by the turbine (b2) during the period of cooling storage is plotted versus the coefficient of performance $C O P$ for time ratio $\Delta t_{s} / \Delta t_{p l}$ of $1.0,2.0,3.0$ and 4.0. $P_{r, s} / P_{b 2, w}$ is independent of both power fraction $R$ and ambient temperature $T_{a}$ as suggested by Eq. (16). It is to be noticed here that the cooling generated by the refrigeration machine is used for two purposes; i.e direct cooling of the wet condenser and storing the cooling thermally for later use at peak loads. Accordingly, the power of the refrigeration machine is relatively high for this period and it may exceed the power of the turbine (b2) at low COP and high values of $R$. In some cases of operating conditions, the power needed for driving the refrigeration machine may become substantially greater than the power generated by the steam plant. To make this clearer, the power ratio $P_{t, s} / P_{t, d}$ calculated by using Eq. (17) is drawn in Figure 8 against the coefficient of performance $C O P$ for time ratio $\Delta t_{s} / \Delta t_{p l}$ of $1.0,2.0$ and 3.0 and for power fraction $R$ of $0.25,0.5,0.75$ and 1.0 at an ambient temperature $T_{a}$ of 25 and $40{ }^{\circ} \mathrm{C}$. The diagrams of Fig. 8 indicate plainly that the effect of the ambient temperature $T_{a}$ on the power ratio $P_{t, s} / P_{t, d}$ is relatively little, where the maximum change in this ratio is about $7 \%$ when $T_{a}$ changes from 25 to $40{ }^{\circ} \mathrm{C}$ and it occurs at $R=1$ and $\Delta t_{s} / \Delta t_{P L}=3.0$. Also, Fig. 8 shows that $P_{t, s} / P_{t, d}$ is raised sharply with increasing $C O P$ for all values of $R$ and $\Delta t_{s} / \Delta t_{p l}$. To assure the availability of enough portion of the plant power for end users, $R$ should not exceed 0.5 
and $\Delta t_{s} / \Delta t_{p l}$ has to be greater than 2.0 when $C O P$ is less than 2.5. This makes more than $50 \%$ of the generated power available for end users. As COP exceeds $2.5 \Delta t_{s} / \Delta t_{p l}$ can be reduced to 1.0 for $R$ less than 0.5 . For this range of $C O P$, higher values of $R$ necessitate elevating $\Delta t_{s} / \Delta t_{p l}$ over 2.0 .

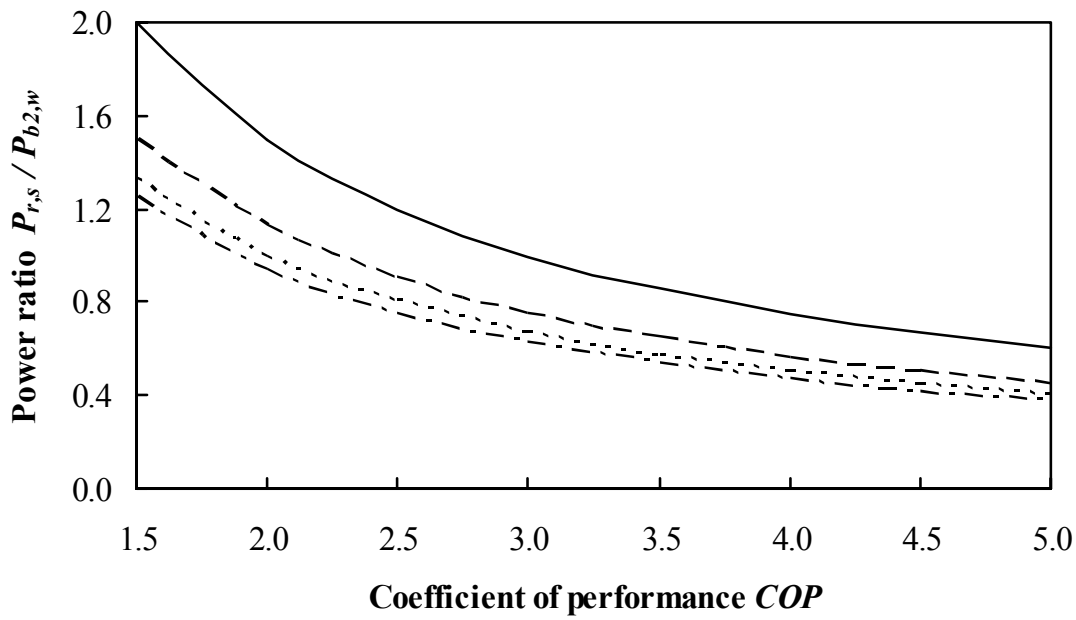

Fig. 7 Average power of the refrigeration machine during cooling thermal storage

$$
\begin{aligned}
& \Delta t_{s} / \Delta t_{p l}=1.0 \\
& \Delta t_{s} / \Delta t_{p l}=3.0
\end{aligned}
$$$$
\begin{array}{ll}
---\Delta t_{s} / \Delta t_{p l}=2.0 \\
-.-.-\Delta t_{s} / \Delta t_{p l}=4.0
\end{array}
$$

It is worthy mentioning here that cooling is stored as ice, chilled water or some other materials. As a tremendous amount of heat must be removed from the wet condenser of the steam plant, ice storing is preferred in this case to limit the volume of the storing container. Nevertheless, the refrigerating machine can be used during the period of storing the cooling to produce both chilled water and ice. Production of chilled water leads to relatively high evaporator temperature and as a result a higher coefficient of performance $C O P$ is achieved. The chilled water serves to cool directly the wet condenser during this period. Production of ice forces the refrigerating machine to work at relatively low evaporator temperature which is inevitable and effects low coefficient of performance $C O P$. Fortunately, the storing process takes place when the end users demand is minimum, which occurs at night hours and early morning, where the ambient temperature has its lowest value. This makes the temperature of the condenser of the refrigerating machine relatively low that partially compensate for the low temperature of the evaporator by remarkably improving the coefficient of performance.

As for the capacity of the cooling storage container, it has been estimated on storing ice to be Ca. $16 \mathrm{~m}^{3}$ for each MW and one hour of the peak-loads of the turbine (b2). This estimation has been based on calculating the heat energy to be removed from the cooling storage container by using Eq. (15) and considering the storage time is zero and the peakload time equals one hour. From this energy the amount of ice formed is calculated.

\section{Concluding Remarks}

In the present work, an approach is proposed to improve the performance of the dry condenser used with a steam power plant. In this approach, two steam turbines are used rather than one turbine. The exhaust steam of the one turbine is cooled in a dry condenser, while the outlet steam of the other turbine is cooled in a wet condenser. The vaporization heat of the wet condenser is rejected in a cooling storage container, which is kept cool by a refrigerating machine. The refrigerating machine has three different operating periods; i.e. 
direct cooling of wet condenser, cooling storage and outage. Simple energy analyses have been developed for predicting the energy output of the combined cooling thermal storage and steam power plant system. On an example of nearly realistic steam plant data the developed analyses were used to study the energy characteristics of the proposed system. In this study, the temperature in the wet condenser was maintained at a design value of 20 ${ }^{\circ} \mathrm{C}$. The results of this study led to drawing the following Conclusions:

a. $\underline{T}_{a}=25^{\circ} \mathrm{C}$

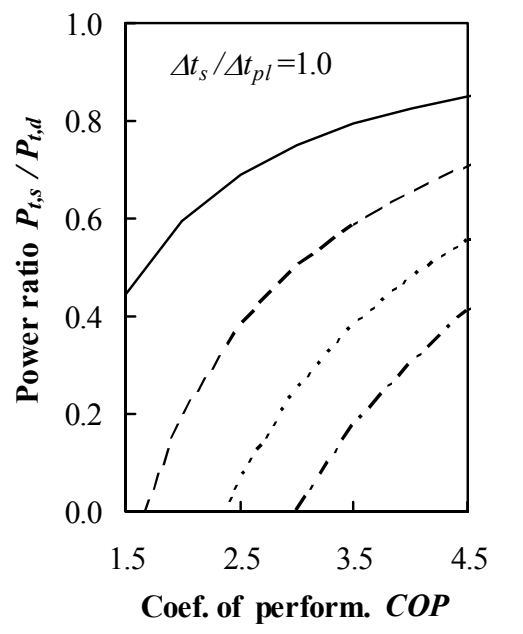

b. $\underline{T}_{a}=40^{\circ} \mathrm{C}$

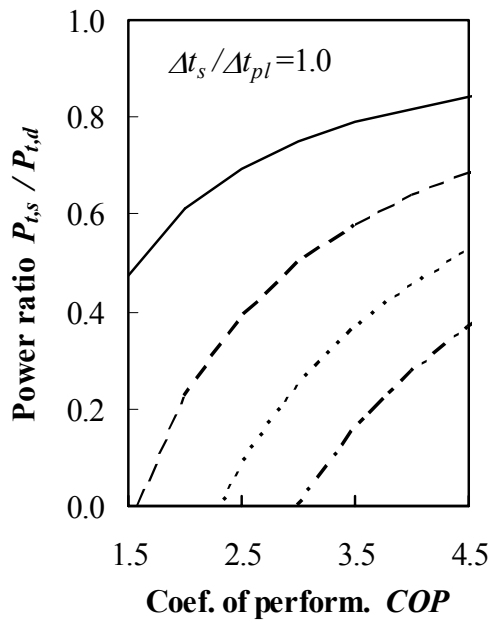

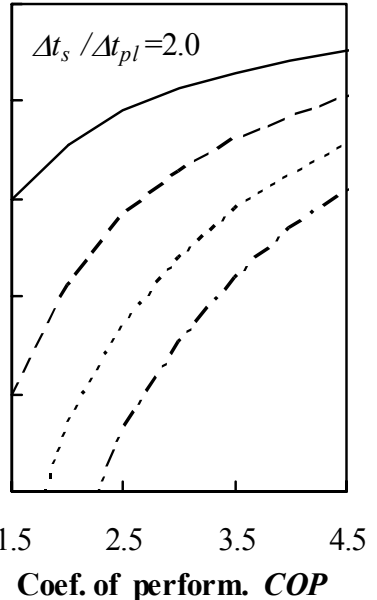

Coef. of perform. COP

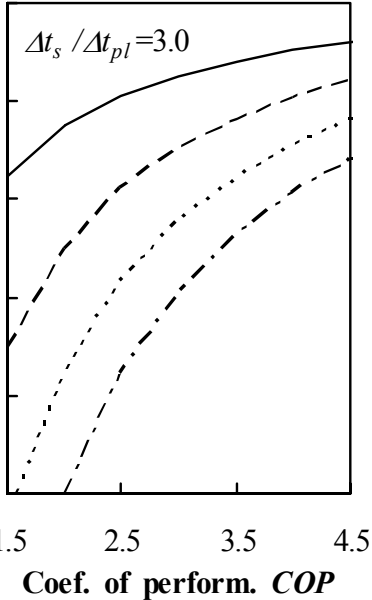

Coef. of perform. COP

Fig. 8 Average net total power of the steam plant during cooling thermal storage
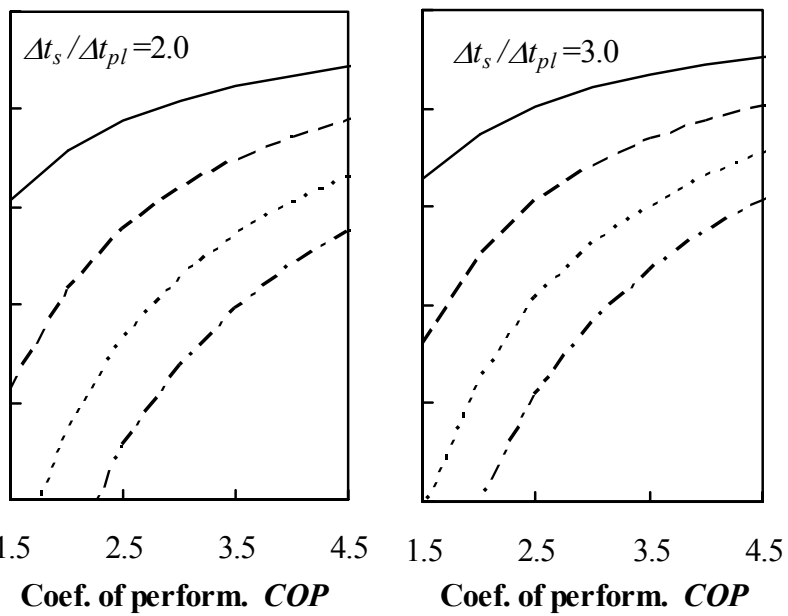

$$
\begin{aligned}
& R=0.25 \\
& R=0.75
\end{aligned}
$$$$
\begin{array}{ll}
---R=0.5 \\
-.-.-R=1.0
\end{array}
$$

1. The net power output of the different configurations of the proposed system is always greater at peak loads than using dry condenser alone.

2. The increase in the power is dependent on the ambient temperature and the ratio of the powers of the two turbines at condenser design temperature.

3. The maximal increase in the plant is achieved when the whole exhaust steam of both turbines is condensed in a wet condenser. In this case, the plant power rises by 6,16 , 24 and $33 \%$ at ambient temperature of $20,30,40$ and $50{ }^{\circ} \mathrm{C}$ respectively. 
4. During the direct cooling of the wet condenser, the refrigeration machine coefficient of performance should be higher than 2.5 to assure high net power generated by the steam plant.

5. During the cooling storage period, if the refrigeration machine coefficient of performance is less than 2.5 , the power of the turbine with wet condenser should be less than 0.5 the total power of the plant at design condition, and the storing time has to be greater than twice the peak-load time. This results in making more than $50 \%$ of the plant generated power available for end users. As the coefficient of performance exceeds 2.5 , the capacity of the turbine with wet condenser can be increased and/ or the storing time can be shortened.

\section{References}

(1) T. J. Feeley, etal., Department of Energy/Office of Fossil Energy's Power Plant Water Management R\&D Program, July (2005).

(2) Bonger, R. and R. Chandron. New Developments in Air-cooled Steam Condensing Palo Alto, CA: EPRI; (1995): Paper 18.

(3) Kroeger, D. G. Air-cooled Heat Exchangers and Cooling Towers. New York: Begell House; 1998.

(4) Balogh, Andras and Z. Takacs. Developing Indirect Dry Cooling Systems for Modern Power Plants [Web Page]. (1998). Available at: http://www.nemesis.at/publication/gpi_98_2/articles/33.html .

(5) Maulbetsch, J. S. and M. N. DiFilippo. Spray Cooling Enhacement of Air-Cooled Condensers, Madadnia, J and H. Koosha. Proceedings of XIIth International Conference on Cooling Towers; Sydney, Australia. International Association of Hydraulic Research; (2001).

(6) Hutton, David. Improved Power Plant Performance with Evaporative Steam Condensing. (1999) Feb; CTI TP99-08.

(7) Conradie, A. E.; J. D. Buys, and D. G. Kröger. Performance Optimization of DryCooling Systems for Power Plants through SQP Methods. Applied Thermal Engineering. (1998); 18(1-2):25-45.

(8) Allemann, R. T.; B. M. Johnson, and E. V. Werry. Wet-Dry Cooling Demonstration: A Transfer of Technology. Palo Alto, CA: Electric Power Research Institute; (1987) Jan; EPRI CS-5016.

(9) Allemann, R. T. et al. Wet-Dry Cooling Demonstration: Test Results. Palo Alto, CA: Electric Power Research Institute; (1986) May; EPRI CS-4321.

(10) Advanced Concepts Test (ACT) Facility Summary Safety Report. Palo Alto, CA: Electric Power Research Institute; (1981) Jul; EPRI CS-1915.

(11) Allemann, R. T. Development of an Advanced Concept of Dry/Wet Cooling of Power Generating Plants. Palo Alto, CA: Electric Power Research Institute; (1981) Feb; EPRI CS-1668.

(12) V. Gadhamshetty, N. Nirmalakhandan, M. Myint, and C. Ricketts, Improving AirCooled Condenser Performance in Combined Cycle Power Plants, J. Energy Engrg., Volume 132, 81 (2006)

(13) Kakaras, E., Doukelis, A., Prelipceau, A., and Karellas, S., Inlet Air Cooling Methods for Gas Turbines Based Power Plants, Journal of Engineering for Gas Turbine and Power, Vol. 128, Issue 2, pp. 312-317, April (2006)

(14) Sonntag, R. E., Borgnakk C., and Van Wylen G. J., "Introduction to Classical Thermodynamics", $4^{\text {th }}$ Edition, John Wiley \& Sons Inc., (1994) 